\title{
Multi-Attribute Three-Stage Procurement Model for Equipment Vendor Selection Decisions
}

\author{
SHU Shao-gan ${ }^{1,}$, , LI Xiao-song ${ }^{2}$ \\ ${ }^{1}$ Postdoctoral Workstation, Equipment Department of Nanjing Military Region, Nanjing, 210016, \\ China \\ ${ }^{2}$ China Defense Science and Technology Information Centre, Beijing 100036, China \\ assg_zzy@qq.com
}

Keywords: Budget; Equipment Vendor; Multi-attribute; Decisions

\begin{abstract}
Equipment procurement had the characteristics of long life cycle, high cost and high technical requirements, and the budget may change. So the problem of how to select equipment vendors under the condition comes on. To improve the efficiency and reducing risk, a model of equipment vendor selections under the condition of budget changing in this paper. What's more, apply the model in exmple of case. Finally, some numerical simulations are made to test the validity and capability of the proposed model.
\end{abstract}

\section{Introduction}

Defense procurement typically requires vendors to submit bids which include price and Performance attributes, however, defense acquisition may face the problem of budget uncertainty, budget may shrink or rise under the long term of acquisition [1-3]. Optimal vendor choice may change with changes in the budget. Therefore, a model is founded to study how to select equipment vendor [4-6].

The rest of the paper is organized in the following sequence. In Section 2, the model structure is introduced in detail. In Section 3, numerical simulation results are made and given to demonstrate the validity of the model. Concluding remarks are summarized in the final section.

\section{The model structure}

The model structure of multiple attribute of supplier selection is displayed in Fig. 1.

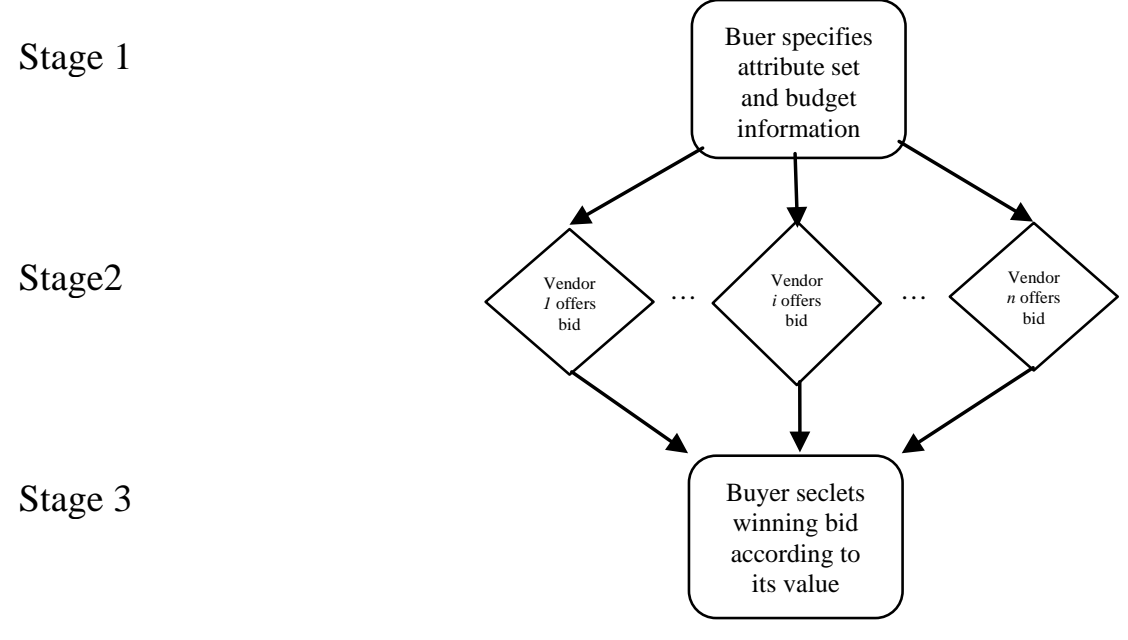

Fig. 1.The multiple attribute of supplier selection

The first step: Department of equipment procurement Solicit opinions performance index of equipment and Issue a tender documents. The documents he paper should contain main contents of two aspects: one is the product performance index of A, two is procurement budget $\mathrm{B}$. 
The second stage: the vendors participate in the competition and provide bidding documents. Vendors' bidding documents included equipment performance index under the budget $\mathrm{B}$. The bidding can be expressed as $A_{i}=\left[a_{i 1}, a_{i 2}, \cdots a_{i m}\right], i=1,2, \cdots n$. where in said, $m$ is product's attributes, $i$ is vendor, $a_{i j}$ is the value of attribute $j$ which is provided by vendor ${ }^{i}$.

The third stage: the procurement department select suppliers. Procurement department should follow the "maximum value" principle to select suppliers,it means that when choosing a supplier should adopt the standards of maximum value function. Value function can be expressed as $V\left(A_{i}\right)$,it is a multi-attribute utility function, attributes are independent of each other.what's more,Each attribute and the utility function are of a linear relationship, each attribute can effectively measure.

Assume: $\mathrm{n}$ vendors; Set of attributes $\mathrm{A}(1, \ldots, \mathrm{m})$; Vendor i 's offer is $A_{i}=\left[a_{i 1}, a_{i 2}, \cdots a_{i m}\right]$; Buyer's "secret" value function (MOE) is $V\left(A_{i}\right)$; Budget level is $\mathrm{B}$; Buyer makes selection decision according to: $\max _{i} V\left(A_{i}\right)=\sum_{j=1}^{m} w_{j} a_{i j}$.

Vendor's Decision Problem: Private information on production capabilities and costs: Captured by cost functions $c_{i j}\left(a_{i j}\right)$ [7-8].

Does not know V, but forms beliefs about the buyer's preferences

- "Best guess" $W_{i}=\left(w_{i 1}, w_{i 2} \cdots w_{i m}\right)$

Results in a hypothetical value function to maximize: $\sum_{j=1}^{m} w_{i j} a_{i j}$

Vendor i 's problem can be expressed as:

and

$$
\max _{a_{i j}} Q\left(A_{i}\right)=\sum_{j=1}^{m} w_{i j} a_{i j}, j=1, \cdots, m
$$

$$
\text { s.t. } T C_{i}=\sum_{j=1}^{m} c_{i j}\left(a_{i j}\right) \leq B
$$

For the sake of clarity, the remainder of the analysis will assume: Two attributes Two vendors. The largrange function is

$$
L_{i}=w_{i 1} a_{i 1}+w_{i 2} a_{i 2}-\lambda_{i}\left(B-c_{i 1}\left(a_{i 1}\right)-c_{i 2}\left(a_{i 2}\right), i=1,2 .\right.
$$

A vendor's best offer (bid) will be a combination of attribute levels that uses the entire budget. Just because of $\frac{\partial Q\left(A_{i}\right)}{\partial a_{i j}}>0$,then satisfies the condition:

$$
\begin{aligned}
& \frac{\partial L_{i}}{\partial a_{i 1}}=w_{i 1}+\lambda_{i} c_{i 1}^{\prime}\left(a_{i 1}\right)=0 \\
& \frac{\partial L_{i}}{\partial a_{i 2}}=w_{i 2}+\lambda_{i} c_{i 2}^{\prime}\left(a_{i 2}\right)=0 \\
& \frac{\partial L_{i}}{\partial \lambda_{i}}=B-c_{i 1}\left(a_{i 1}\right)-c_{i 2}\left(a_{i 2}\right)=0
\end{aligned}
$$

Accrdong to (4a)、(4b)and (4c),

$$
\frac{w_{i 1}}{C_{i 1}^{\prime}\left(a_{i 1}\right)}=\frac{w_{i 2}}{c_{i 2}^{\prime}\left(a_{i 2}\right)}
$$

The buyer then chooses the vendor that maximizes its military effectiveness value $\mathrm{V}$ for the planned budget, $\mathrm{B}$. 
Now, instead of B, consider a range of possible budgets: $B_{1}, \cdots B_{k}$

Each vendor submits an offer (bid) for each of the k possible budgets.

This set of offers from a vendor constitutes an “expansion path”.

\section{Simulation and analysis}

Suppose that the vendors have cost functions of the form:

$$
\begin{gathered}
c_{i j}\left(a_{i j}\right)=\alpha_{i j} e^{\beta_{i j} a_{i j}} \alpha_{i j}, \beta_{i j}>0 \\
\alpha_{11}=\alpha_{12}=2.0, \beta_{11}=\beta_{12}=0.6 \quad \alpha_{21}=\alpha_{22}=1.0, \beta_{21}=\beta_{22}=1.0 \quad w_{11}=0.7, w_{21}=0.7
\end{gathered}
$$

We will examine several cases where the vendors differ in their cost functions and/or beliefs about the weight the buyer places on the attributes. The results of the different cases are illustrated as the Fig.2, Fig.3 and Fig.4, respectively.

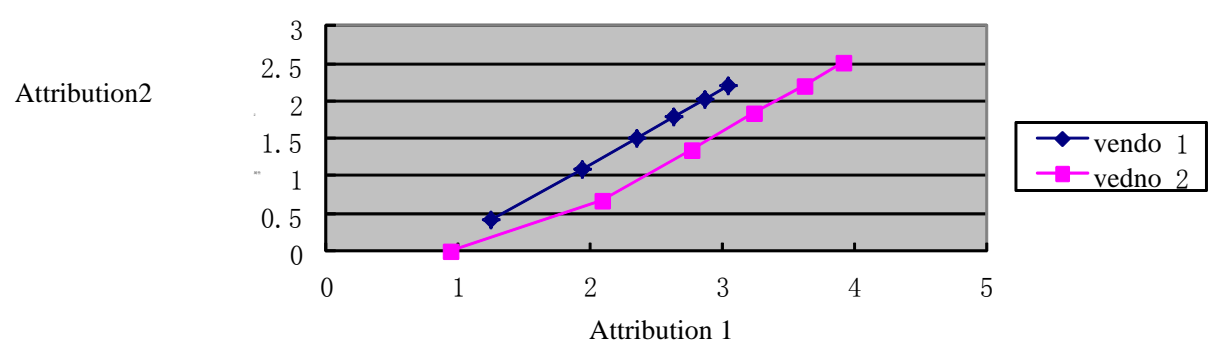

Fig.2 Expansion Paths-Differing Cost Functions

Suppose that the vendors have cost functions of the form:

$$
\begin{gathered}
c_{i j}\left(a_{i j}\right)=\alpha_{i j} e^{\beta_{i j} a_{i j}} \quad \alpha_{i j}, \beta_{i j}>0 \\
\alpha_{11}=\alpha_{12}=\alpha_{21}=\alpha_{22}=2.0 \quad \beta_{11}=\beta_{12}=\beta_{21}=\beta_{22}=0.6 \quad w_{11}=0.5 \quad w_{21}=0.7
\end{gathered}
$$

Attribution 2

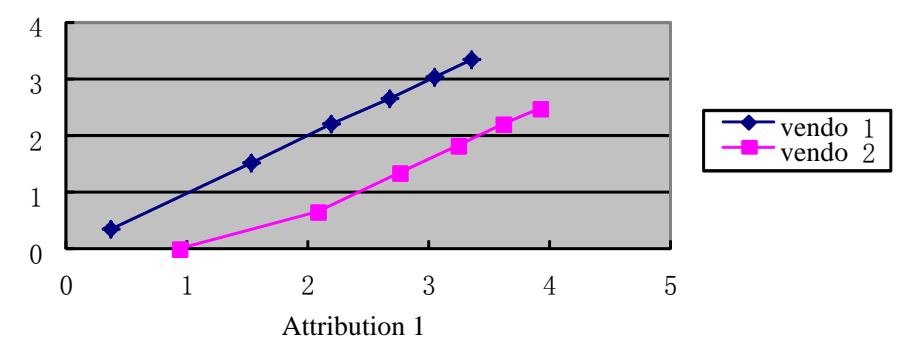

Fig.3 Expansion Paths-Differing Beliefs

Suppose that the vendors have cost functions of the form:

$$
\begin{gathered}
c_{i j}\left(a_{i j}\right)=\alpha_{i j} e^{\beta_{i j} a_{i j}} \alpha_{i j}, \beta_{i j}>0 \\
\alpha_{11}=\alpha_{12}=2.0 \beta_{11}=\beta_{12}=0.6 \alpha_{21}=\alpha_{22}=1.0 \beta_{21}=\beta_{22}=1 w_{11}=0.5, \quad w_{21}=0.7
\end{gathered}
$$

Attribution2

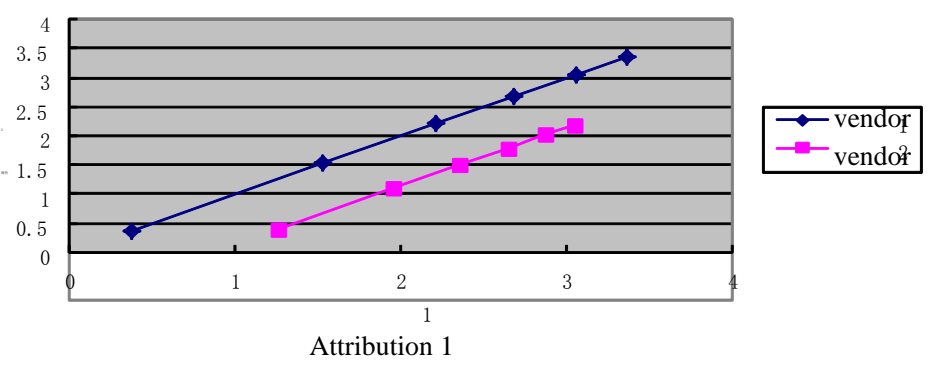

Fig.4 Expansion Paths-Differing Beliefs and Cost Functions 
Switch to Budget-Value Space, What is the value to the buyer (procurement agency; war fighter) provided by each vendor for a specific budget authority? What is the value to the buyer provided by each vendor over all possible budget levels?

Assume the two vendors have the properties from the last graph, and that the buyer places a weight of 0.7 on attribute 1 .

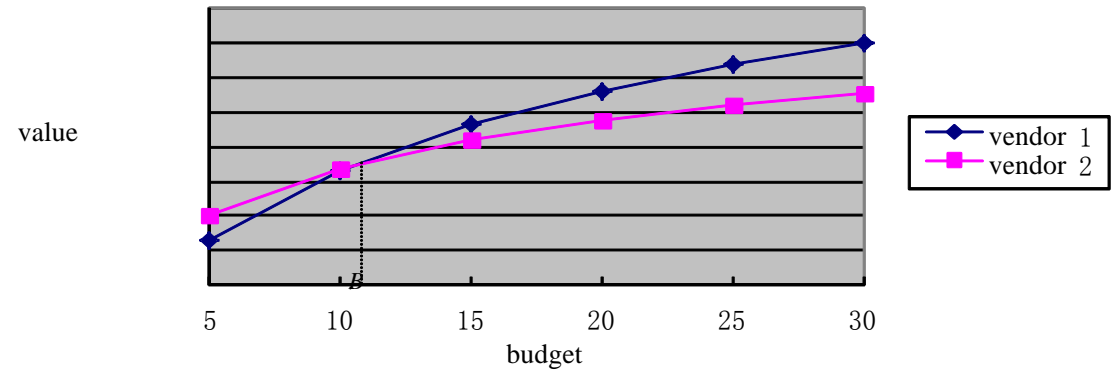

Fig.5 Traditional Price \& Performance Bid

As we can see from Figure 5, when the actual budget, $B<B^{\prime}, 2$ suppliers always occupied the dominant position, when the dominant supplier $B>B^{\prime}, 1$.

Through the above analysis, we need to reconsider the methods, determine the supplier of the traditional budget -- in fact, using the value way to observe the selection of suppliers, reveals the traditional evaluation method to determine the supplier may have errors. For example, in an optimistic budget standard, namely, the traditional technology is focused on this points, this will most likely exclude suppliers 2. But from Figure 5 we can clearly see that, when the budget value is too optimistic, and the true budget range in, exclude suppliers 2choice is wrong.

\section{Conclusion}

Model the budget uncertainty with a probability distribution, and determine the expected utility provided by each vendor. Include uncertainty in vendor performance (quantity, quality, schedule) promises. May be framed as either cost uncertainty or performance uncertainty or both (depends on the particular contract structure). Whenever any of the two suppliers of property is not the same curve, two vendor and two attrubition is just a e example for express clarity. By this model, equipment procurement management can observe vendors' react to different changes in the budget, the model could do help choosing the best vendor.

\section{References}

[1] O'Rourke R. The Impact of Chinese Naval Modernization on the Future of the United States Navy[M]. Nova Publishers, 2006.

[2] Taylor E S. BLOOD PROCUREMENT FOR THE ARMY AND NAVY: PRELIMINARY REPORT[J]. Journal of the American Medical Association, 1941, 117(25): 2123-2129.

[3] Friedman B, Preble C. Budgetary savings from military restraint[J]. Cato Institute Policy Analysis, 2010 (667).

[4] Law J, Callon M. Engineering and sociology in a military aircraft project: A network analysis of technological change[J]. Social problems, 1988, 35(3): 284-297.

[5] Rosenbloom R S. Leadership, capabilities, and technological change: The transformation of NCR in the electronic era[J]. Strategic Management Journal, 2000, 21(10-11): 1083-1103.

[6] Liu H, Jiang Y. Technology transfer from higher education institutions to industry in China: nature and implications[J]. Technovation, 2001, 21(3): 175-188.

[7] Davidrajuh R. Modeling and implementation of supplier selection procedures for e-commerce initiatives[J]. Industrial Management \& Data Systems, 2003, 103(1): 28-38. 
[8] Luo X, Wu C, Rosenberg D, et al. Supplier selection in agile supply chains: An information-processing model and an illustration[J]. Journal of Purchasing and Supply Management, 2009, 15(4): 249-262. 